\section{AB0024 IN VITRO CHARACTERIZATION OF CENERIMOD, A POTENT AND SELECTIVE SPHINGOSINE 1-PHOSPHATE RECEPTOR 1 (S1P1) MODULATOR IN PREVENTING MIGRATION OF NON-ACTIVATED AND ACTIVATED PRIMARY HUMAN B CELLS IN THE PRESENCE OR ABSENCE OF GLUCOCORTICOIDS}

L. Schlicher ${ }^{1}$, P. Kulig ${ }^{1}$, M. Murphy ${ }^{1}$, M. Keller ${ }^{1} .{ }^{1}$ Idorsia Pharmaceuticals Ltd, Immunology, Basel, Switzerland

Background: Cenerimod is a potent, selective, and orally active sphingosine 1-phosphate receptor $1\left(\mathrm{~S}_{1} \mathrm{P}_{1}\right)$ modulator that is currently being evaluated in a Phase $2 \mathrm{~b}$ study in patients with systemic lupus erythematosus (SLE) (NCT03742037). S1P receptor modulators sequester circulating lymphocytes within lymph nodes, thereby reducing pathogenic autoimmune cells (including B lymphocytes) in the blood stream and in inflamed tissues. Extensive clinical experience has become available for the nonselective S1P receptor modulator fingolimod in relapsing forms of multiple sclerosis, supporting this therapeutic concept for the treatment of autoimmune disorders. Objectives: Although the effect of S1P-receptor modulators in reducing peripheral $B$ cells is well documented ${ }^{1,2}$, the role of the S1P, receptor on this cell type is only incompletely understood. In this study, the mode of action of cenerimod on primary human B cells was investigated in a series of in vitro experiments, including S1P receptor cell surface expression and chemotaxis towards S1P. Moreover, S1P expression following B cell activation in vitro was studied. As glucocorticoids (GC) are frequently used in the treatment of patients with autoimmune disorders including SLE, the potential influence of GC on the mode of action of cenerimod was evaluated. Methods: Primary human B lymphocytes from healthy donors were isolated from whole blood. In one set of experiments, cells were treated with different concentrations of cenerimod to measure S1P, receptor internalization by flow cytometry. In a second set of experiments, isolated B cells were activated using different stimuli or left untreated. Cells were then analysed for $\mathrm{S}_{1} \mathrm{P}_{1}$ and CD69 cell surface expression and tested in a novel real-time S1P-mediated migration assay. In addition, the effect of physiological concentrations of GCs (prednisolone and prednisone) on cenerimod activity in preventing S1P mediated migration was tested.

Results: In vitro, cenerimod led to a dose-dependent internalization of the S1P receptor on primary human $B$ lymphocytes. Cenerimod also blocked migration of nonactivated and activated B lymphocytes towards S1P in a concentration-dependent manner, which is in line with the retention of lymphocytes in the lymph node and the reduction of circulating lymphocytes observed in the clinical setting. Upon B cell activation, which was monitored by CD69 upregulation, a simultaneous downregulation of $\mathrm{S}_{1} \mathrm{P}_{1}$ expression was detected, leading to less efficient S1P-directed cell migration. Importantly, physiological concentrations of GC did not affect the inhibitory activity of cenerimod on B cell migration.

Conclusion: These results show that cenerimod, by modulating $\mathrm{S}_{1} \mathrm{P}_{1}$, blocks $\mathrm{B}$ lymphocyte migration towards its natural chemoattractant S1P and demonstrate compatibility of cenerimod with GC. These results are consistent with results of comparable experiments done previously using primary human $T$ lymphocytes. REFERENCES:

[1] Nakamura M et al., Mult Scler. 2014 Sep; 20(10):1371-80.

[2] Strasser DS et al., RMD Open 2020;6:e001261.

Disclosure of Interests: None declared

DOI: 10.1136/annrheumdis-2021-eular.2482

\section{AB0025 CITRULLINATED-PEPTIDE SPECIFIC CD4+ T CELL RESPONSES IN RHEUMATOID ARHRITIS}

J. Swift ${ }^{1}$, J. Stanway ${ }^{1}$, I. Nicorescu ${ }^{1}$, C. Hilkens ${ }^{1}$, F. Stevenaert ${ }^{2}$, A. Anderson ${ }^{1}$, A. Pratt ${ }^{1}$, J. D. Isaacs ${ }^{1}{ }^{1}$ Newcastle University, Translational and Clinical Research Institute, Newcastle-upon-Tyne, United Kingdom; ${ }^{2}$ Janssen Pharmaceutica, Immunosciences, Beerse, Belgium

Background: CD4+ T cells reacting to post-translationally modified, citrullinated self-antigens are thought to play a central role in the pathogenesis of rheumatoid arthritis (RA) ${ }^{1}$. This is evidenced by a strong HLA class II association, the success of therapeutic co-stimulation blockade and the detection of autoantigen specific T-cells using HLA class II multimers ${ }^{2}$. These cells may represent a target for antigen-specific, tolerogenic therapies and their in-depth phenotyping may provide the means by which to monitor such treatment. Objectives: To identify the citrullinated-peptide (cit-peptide) induced cytokine repertoire of antigen-specific memory CD4+ T cells in both healthy controls (HCs) and ACPA positive RA patients using intracellular cytokine staining and flow cytometry. Of note, the HLA-types of both HCs and RA patients were not known. Methods: Cryopreserved peripheral blood mononuclear cells (PBMC) from both HCs $(n=8)$ and RA patients $(n=13)$ with both early (untreated) and established disease were thawed and labelled with a proliferation tracking dye (PTD). Labelled PBMC were then either incubated alone or with a pool of cit-peptides for 9-days, followed by a 5-hour restimulation with PMA and ionomycin, where cytokine secretion was blocked for the final 4-hours using brefeldin-A. Cells were then harvested, permeabilised and stained for $T$ cell surface markers and intracellular cytokines including IFN- $\gamma, \mathrm{IL}-4, \mathrm{IL}-21$ and IL-17. Stained cells were immediately acquired using a BD Fortessa X20, where antigen-specific CD4+ T cells were identified as the viable CD45RO+ (memory) CD4+ T cell population that had proliferated (PTDlow) in response to the cit-peptides. Stimulation indices (SI) were calculated as the percentage of proliferated memory CD4+ T cells in the stimulated wells divided by the percentage in the unstimulated conditions, and cit-peptide responders were defined as those with an $\mathrm{SI}>2.0$. Net cytokine production was measured by subtracting the percentage cytokine production from unstimulated CD4+ CD45RO+ PTDlow cells, from those stimulated with the cit-peptides.

Results: Comparable proliferative responses were observed in both donor groups in response to stimulation with the cit-peptide pool, where $37 \%$ of $\mathrm{HCs}$ and $31 \%$ of RA patients responded with an $\mathrm{SI}>2.0$ (Fig. 1A). While little cytokine production was observed in the cit-peptide responding $\mathrm{HC}$ T cells, for responding RA donors, cit-peptide responsive CD4+ memory $\mathrm{T}$ cells were predominantly IFN- $\gamma$ and IL-21 producing (Fig. 1B and 1C). In contrast, these donors did not produce significant levels of either IL-17 or IL-4 (Fig. 1D and 1E).

Conclusion: Cit-peptides were able to induce proliferation in both $\mathrm{HCs}$ and RA memory CD4+ T cells which, amongst the RA donors only, were of a Th1/Tfh subtype. In contrast, and while based only on a small sample, cit-peptides did not induce either IL-17 or IL-4 production in either donor group, suggesting a lack of Th17/Th2 responses. Not all donors responded to the peptide pool, possibly reflecting the limited number of pooled cit-peptides or to a lack of confirmed HLA-DRB1*04:01 positive donors, as peptides were selected for their specificity on this basis. Future work will therefore include HLA-typing, as well as the inclusion of additional citrullinated-epitopes to demonstrate autoreactivity in a wider cross-section of patients. Further phenotyping of the cit-peptide specific T cells will be performed, and future plans will be to study the assay data alongside clinical outcomes to assess its value for immune monitoring. REFERENCES:

[1] Malmström, V et al Nat Rev Immunol. 2017; 17(1):60-75.

[2] Gerstner, C et al BMC Immunol. 2020; 21(27):1-14.

Disclosure of Interests: Jessica Swift: None declared, James Stanway: None declared, loana Nicorescu: None declared, Catharien Hilkens: None declared, Frederik Stevenaert Employee of: Janssen, Amy Anderson Grant/research support from: Pfizer, GSK and Janssen, Arthur Pratt Grant/research support from: Pfizer, GSK and Janssen, John D Isaacs Speakers bureau: Abbvie, Gilead, Roche, UC, Consultant of: Abbvie, Gilead, Roche, UC, Grant/research support from: Pfizer, GSK and Janssen
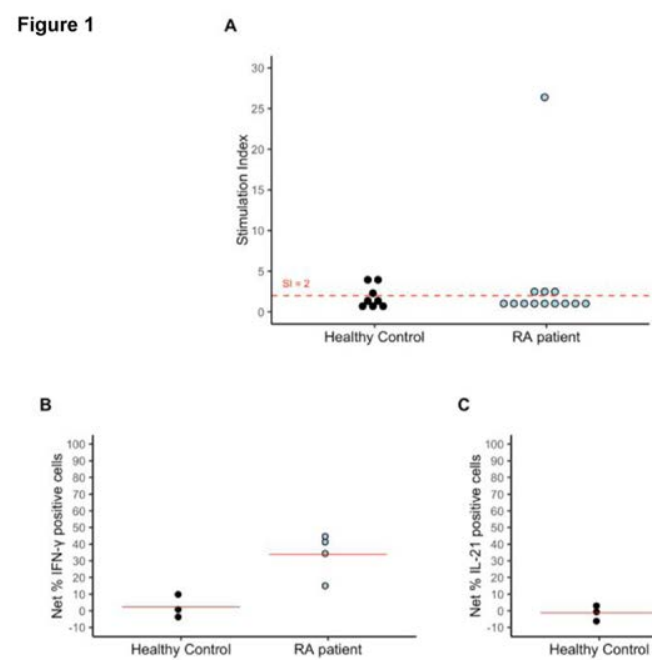

c
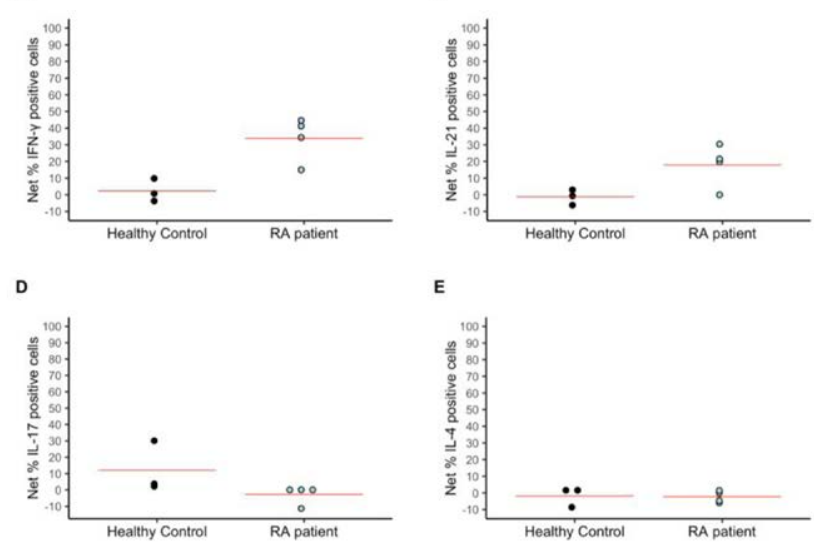

Figure 1. Citrullinated-peptide specific memory CD4+ T cell proliferation (A) and net $\%$ cytokine production of IFN- $\gamma(B)$, IL-21 (C), IL-17 (D) and IL-4 (E) positive cells. DOI: 10.1136/annrheumdis-2021-eular.2652

\begin{tabular}{l|l}
\hline AB0026 & DECREASE OF ANGIOGENIC T CELLS IN \\
CONNECTIVE TISSUE DISEASE-ASSOCIATED \\
INTERSTITIAL LUNG DISEASE
\end{tabular}

V. Pulito-Cueto $^{1}$, S. Remuzgo Martinez ${ }^{1}$, F. Genre $^{1}$, B. Atienza-Mateo ${ }^{1,2,3}$, V. M. Mora-Cuesta ${ }^{1,4}$, D. Iturbe-Fernández ${ }^{1,4}$, L. Lera-Gómez ${ }^{1}$, R. Pérez-Fernández ${ }^{1}$, 